\title{
Refractory Lung Carcinoma
}

National Cancer Institute

\section{Source}

National Cancer Institute. Refractory Lung Carcinoma. NCI Thesaurus. Code C141076.

Lung carcinoma that does not respond to treatment. 